\title{
Prevalence of serum antibodies to caudate nucleus in autistic children
}

\author{
Vijendra K. Singh*, Wyatt H. Rivas \\ Department of Biology, Biotechnology Center Building, Utah State University, 4700 Old Main Hill, Logan, UT 84322-4700, USA
}

Received 3 July 2003; received in revised form 15 October 2003; accepted 15 October 2003

\begin{abstract}
Autism may involve autoimmunity to brain. We studied regional distribution of antibodies to rat caudate nucleus, cerebral cortex, cerebellum, brain stem and hippocampus. The study included 30 normal and 68 autistic children. Antibodies were assayed by immunoblotting. Autistic children, but not normal children, had antibodies to caudate nucleus (49\% positive sera), cerebral cortex (18\% positive sera) and cerebellum ( $9 \%$ positive sera). Brain stem and hippocampus were negative. Antibodies to caudate nucleus were directed towards three proteins having 160, 115 and $49 \mathrm{kD}$ molecular weights. Since a significant number of autistic children had antibodies to caudate nucleus, we propose that an autoimmune reaction to this brain region may cause neurological impairments in autistic children. Thus, the caudate nucleus might be involved in the neurobiology of autism.
\end{abstract}

(C) 2003 Elsevier Ireland Ltd. All rights reserved.

Keywords: Autism; Autoimmunity; Caudate nucleus; Antibodies; Neurobiology

Autism is an early-onset disorder of the developing central nervous system (CNS). The disorder causes severe deficits of higher mental functions such as social interaction, language, communication, imagination and cognition. Today, autism is the fastest-growing developmental disability in children. Autism affects more than one-half of a million Americans and millions more worldwide but very little is known about the etiology and pathogenesis of the disorder. Current theories include genetic factors, immune factors, environmental factors and yet other unidentified factors. We focused on immune factors such as autoimmunity and provided supporting evidence for 'autoimmune hypothesis' in autism [9-14]. Autoimmunity in autistic children is shown by several autoimmune factors: brain-specific antibodies [10], impaired lymphocyte functions [3,6,15-17], abnormal cytokine regulation [11], viral associations [10,12,13] and indirect association of certain immunogenetic factors [16]. In the present study, our goal was to determine if autistic children harbor brain-specific antibodies, particularly with regards to different brain regions. We selected five brain regions for our study: caudate nucleus $(\mathrm{Cn})$, cerebral cortex $(\mathrm{Cx})$, cerebellum $(\mathrm{Cb})$, brain stem $(\mathrm{Bs})$ and hippocampus $(\mathrm{Hpc})$. Laboratory results

\footnotetext{
* Corresponding author. Tel.: + 1-435-797-7193; fax: + 1-435-797-2766.

E-mail address: singhvk@cc.usu.edu (V.K. Singh).
}

described here provide initial evidence for an autoimmune reaction to caudate nucleus in children with autism.

The study included 68 autistic children aged 4-12 years and 30 normal children aged 5-12 years. Of the 68 autistic children, eight had a diagnosis of pervasive developmental disorder (PDD) and the remainder 60 cases had a diagnosis of autism. The clinical diagnosis of autism and/or PDD relied essentially on the standard DSM-IV criteria of the American Association of Psychiatrists, Washington, DC. The Institutional Review Board or the ethical committee of Utah State University reviewed and approved our research protocol that involved the use of blood samples from children. All children were at the baseline without any treatment with prescription medications at the time of blood collection or at least 2 weeks prior to it.

Brain antibodies were detected by our standard immunoblotting technique [10,13]. Sprague-Dawley rats were sacrificed to remove brain, which was dissected to collect $\mathrm{Cn}, \mathrm{Cx}, \mathrm{Cb}, \mathrm{Bs}$ and $\mathrm{Hpc}$ regions. Each brain region was separately homogenized in Tris-buffered saline containing $0.05 \%$ Tween-20 (TBST) and stored frozen at $-20{ }^{\circ} \mathrm{C}$. Neural proteins were separated in $12 \%$ Ready Gels (Bio-Rad, Richmond, CA) by sodium dodecyl sulfate-polyacrylamide gel electrophoresis, transferred to nitrocellulose membranes by the double sandwich technique, followed by blocking with $1 \%$ bovine serum albumin in TBS. For immunoassay, 3-4 
$\mathrm{mm}$ wide blots were incubated with a screening dilution of 1:25 of patient or control sera for $1 \mathrm{~h}$. They were washed four times with TBST, followed by $1 \mathrm{~h}$ incubation with 1:2500 diluted alkaline phosphatase conjugated-goat anti-human polyvalent immunoglobulins (Sigma, St. Louis, MO). After four washings with TBST, the blots were developed in substrate solution according to instructions from the manufacturer of the AP substrate kit (Bio-Rad). A reaction was scored positive only if a purplish-blue band appeared. To prevent potential bias, all samples were analyzed in a doubleblind fashion and the code was broken after the completion of the laboratory analysis. For molecular weight determination, we used kaleidoscope pre-stained protein standards (Bio$\mathrm{Rad})$ that included myosin $(237 \mathrm{kD}), \beta$-galactosidase (134 $\mathrm{kD})$, bovine serum albumin $(85 \mathrm{kD})$, carbonic anhydrase (43.1 kD), trypsin soyabean inhibitor (32 kD), lysozyme $(17.4 \mathrm{kD})$ and aprotinin $(7.2 \mathrm{kD})$.

Immunoblotting screen showed antibody positive reactions to neural proteins of the $\mathrm{Cn}, \mathrm{Cx}$ and $\mathrm{Cb}$. Autistic serum showed a positive reaction but normal serum did not (Fig. 1). We found that the highest number of antibody-positive autistic sera was with the $\mathrm{Cn}$ region $(49 \%)$ as compared to $\mathrm{Cx}$ region (18\%) or $\mathrm{Cb}$ region $(9 \%)$ (Fig. 2). All sera were negative for antibodies to $\mathrm{Bs}$ and $\mathrm{Hpc}$ regions either because there was no antibody reaction (as with Bs region) or it was non-specific and indistinguishable between patients and controls (as with Hpc region). This finding suggests that the neurons in the caudate nucleus might be a target of autoimmune pathology in autism.

Because Cn was the most immunoreactive brain region,
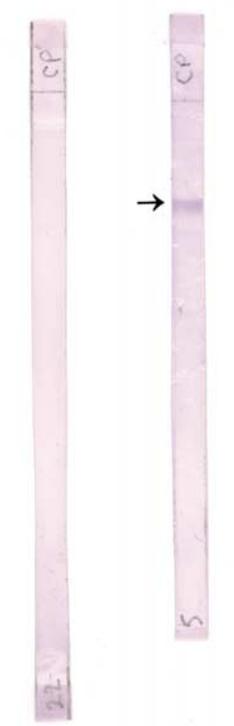

Normal
Serum

Normal Autistic Serum $\underline{\text { Serum }}$
Autistic children $(n=68)$ Normal children $(n=30)$

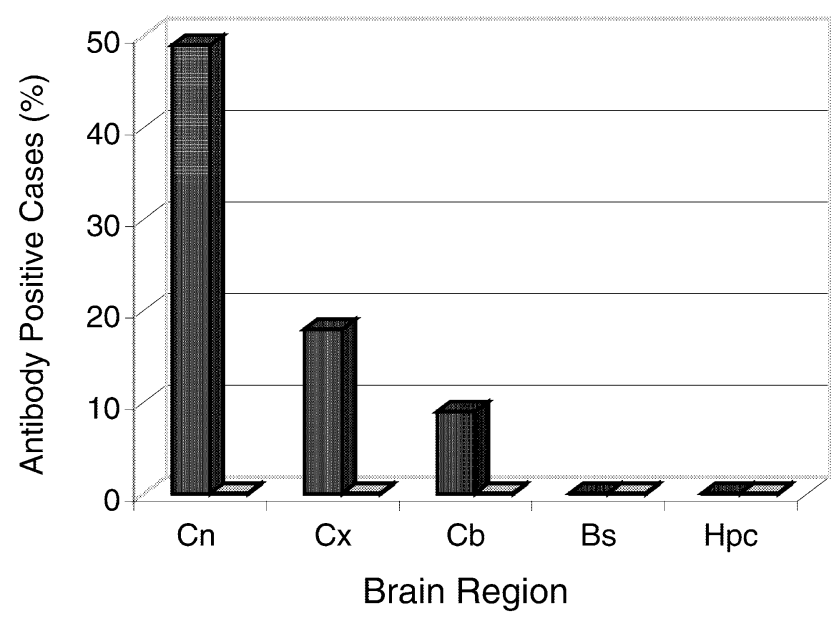

Fig. 2. Distribution of anti-brain antibodies in autistic and normal children. The data is given as the percentage of sera positive for antibodies to each brain region. Note that the highest number of antibody-positive autistic cases was with caudate nucleus.

an attempt was made to extract proteins from this region. The protein gel pictures are not included here but the protein patterns of $\mathrm{Cn}$ homogenate and $\mathrm{Cn}$ supernatant $(\mathrm{CnS})$ resembled quite closely. As shown in Fig. 3, antibodies in autistic sera reacted with two major proteins of $\mathrm{Cn}$ homogenate having molecular weight of approximately 160,000 (band A) and 115,000 (band B). These two proteins also showed positive reactions with $\mathrm{CnS}$ but an additional protein band (band C) was positive at a molecular weight of

\section{Caudate Nucleus Cerebral Cortex Cerebellum}

Fig. 1. Typical blots showing antibody reactions against proteins of the caudate nucleus, cerebral cortex, and cerebellum. As shown by black arrows, there were antibody-positive bands in autistic children (blots on the right hand side) but not in normal children (blots on the left hand side). 

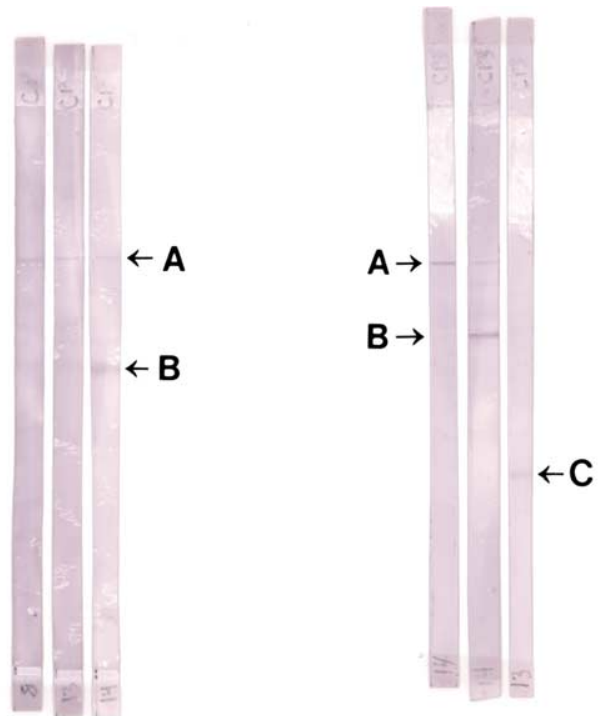

$\underline{\text { Autistic Sera }}$

$\underline{\text { Autistic Sera }}$

\section{Caudate Nucleus $\rightarrow$ Caudate Nucleus Supernatant (Cn) (CnS)}

Fig. 3. Representative blots showing antibody positive reactions of caudate nucleus with autistic sera. As shown by black arrows, there were two antibody-positive proteins (bands A and B) in the caudate nucleus (left hand blots) and caudate nucleus supernatant (right hand blots), but the antibody reaction also occurred with an additional protein (band $\mathrm{C}$ ) of the caudate nucleus supernatant.

approximately 49,000 (Fig. 3). Considering the fact that $\mathrm{Cn}$ and $\mathrm{CnS}$ contain a large number of proteins, it is interesting to find only two to three proteins positive for antibodies. This must imply a significant level of specificity with respect to autoantigens. To that end, it is worth noting that the caudate nucleus is enriched with serotonergic receptors [7], and antibodies to serotonergic receptors have been found in autistic children [14]. Naturally, while other possibilities exist, we think it is instructive to consider the possibility of an autoimmune reaction to serotonergic nerveendings of the caudate nucleus. Once they have been fully characterized, these proteins could potentially serve as markers of neuropathology in autism. This topic is currently under investigation in our laboratory.

Studies of autistic brain are extremely rare despite pathognomic manifestations in people affected with the disorder. Brain autopsies, albeit of only a few cases, have shown size reduction in brainstem [5] and loss of cellular density of Purkinje Cells in the cerebellum [8]. The other abnormalities include limbic structures and forebrain [1]. Magnetic resonance imaging studies have shown hypoplasia of cerebellar vermal lobules VI and VII [2]. Delayed maturation of the frontal cortex [18] and developmental abnormalities of the myelin sheath [10] have been described in the brain of autistic children. As reported here, we did not find antibodies to brainstem or hippocampus and only a few cases had antibodies to cerebellum or cerebral cortex. This finding may indicate that autoimmune process is probably not the reason for abnormalities in these regions of the autistic brain. Besides these regions, we found antibodies to caudate nucleus in approximately one-half of the autistic children, which is a significantly high number of cases that we studied. These antibodies may impair neuronal functions in caudate nucleus thereby manifest neurological and behavioral symptoms in children with autism. Some credence to this line of thinking may come from a recent study of Tourette syndrome children who also harbor antistriatal antibodies; upon infusion into the rat striatum, these antibodies caused neuronal dysfunction that was similar to the one found in Tourette syndrome children [4]. While the further characterization of Cn-derived autoantigens is in progress, we think that this new immunological evidence may suggest the involvement of caudate nucleus in the neuropathology of childhood autism.

\section{Acknowledgements}

This research was supported by small grants from the BHARE Foundation, Duddley Dougherty Foundation, and Autism Research Institute. Wyatt Rivas was an honors student in biology.

\section{References}

[1] M.L. Bauman, Microscopic neuroanatomic abnormalities in autism, Pediatrics 87 (1991) 791-796.

[2] E. Courchesne, R. Yeung-Courchesne, G.A. Press, J.R. Hesselink, T.L. Jerningan, Hypoplasia of cerebellar vermal lobules VI and VII in autism, N. Engl. J. Med. 318 (1988) 1349-1354.

[3] S. Gupta, S. Aggarwal, C. Heads, Dysregulated immune system in children with autism: Beneficial effects of intravenous immune globulin on autistic characteristics, J. Aut. Dev. Disord. 26 (1996) 439-452.

[4] J.J. Hallett, C.J. Harling-Berg, P.M. Knopf, E.G. Stopa, L.S. Kiessling, Anti-striatal antibodies in Tourette syndrome cause neuronal dysfunction, J. Neuroimmunol. 111 (2000) 195-202.

[5] T. Hashimoto, M. Tayama, M. Miyazaki, N. Sakurama, T. Yoshimoto, K. Murakawa, Y. Kuroda, Reduced brainstem size in children with autism, Brain Dev. 14 (1992) 94-97.

[6] P. Menage, G. Thibault, C. Barthelemy, G. Lelord, P. Bardos, CD4 + CD45RA $+\mathrm{T}$ lymphocyte deficiency in autistic children: effect of a pyridoxine-magnesium treatment, Brain Dysfunct. 5 (1992) 326-333.

[7] J.M. Palacios, C. Waeber, D. Hoyer, G. Mengod, Distribution of serotonin receptors, Ann. N. Y. Acad. Sci. 600 (1990) 36-52.

[8] E.R. Ritvo, B.J. Freeman, A.B. Scheibel, T. Duong, H. Robinson, D. Guthrie, A. Ritvo, Lower Purkinje cell counts in the cerebella of four autistic subjects: initial findings of the UCLA-NSAC autopsy research report, Am. J. Psychiatry 143 (1986) 862-866.

[9] V.K. Singh, Immunotherapy for brain disease and mental illnesses, Prog. Drug Res. 48 (1997) 129-146.

[10] V.K. Singh, Neuro-immunopathogenesis in autism, in: I. Berczi, R.M. Gorczynski (Eds.), NeuroImmune Biology: New Foundation of Biology, 1, Elsevier, Amsterdam, 2001, pp. 443-454.

[11] V.K. Singh, Cytokine regulation in autism, in: Z. Kronfol (Ed.), Cytokines and Mental Health, Kluwer Academic Publishers, Boston, 2003, pp. 369-383. 
[12] V.K. Singh, R.L. Jensen, Elevated levels of measles antibodies in children with autism, Pediatr. Neurol. 28 (2003) 292-294.

[13] V.K. Singh, S.X. Lin, E. Newell, C. Nelson, Abnormal measlesmumps-rubella antibodies and CNS autoimmunity in children with autism, J. Biomed. Sci. 9 (2002) 359-364.

[14] V.K. Singh, E.A. Singh, R.P. Warren, Hyperserotoninemia and serotonin receptor antibodies in children with autism but not mental retardation, Biol. Psychiatry 41 (1997) 753-755.

[15] E.G. Stubbs, M.L. Crawford, D.R. Burger, A.A. Vanderbark, Depressed lymphocyte responsiveness in autistic children, J. Autism Child. Schizophr. 7 (1977) 49-55.
[16] R.P. Warren, A. Foster, N.C. Margaretten, Reduced natural killer cell activity in autism, J. Am. Acad. Child Adol. Psychol. 26 (1987) 333-335.

[17] R.P. Warren, V.K. Singh, R.E. Averett, J.D. Odell, A. Maciulis, R.A. Burger, W.W. Daniels, Immunogenetic studies in autism and related disorders, Mol. Chem. Neuropathol. 28 (1996) 77-81.

[18] M. Zilbovicius, B. Garreau, Y. Samson, P. Remy, C. Berthelemy, A. Syrota, G. Lelord, Delayed maturation in the frontal cortex in childhood autism, Am. J. Psychiatry 152 (1995) 248-252. 